\title{
Synthesis of activated carbon derived from chicken feather for Li-ion batteries through chemical and physical activation process
}

\author{
Erna Hastuti $^{1}$ (1) $\cdot$ Achmad Subhan $^{2} \cdot$ Devi Puspitasari $^{1}$
}

Received: 6 March 2021 / Accepted: 9 August 2021 / Published online: 15 August 2021

(c) The Author(s) 2021

\begin{abstract}
The use of activated carbon from biomass as an electrode for lithium-ion batteries is promising because of the low cost, natural abundance, and environmentally friendly. Chicken feather is a biomass that has the potential to be a source of activated carbon, because it contains keratin. The activation process affects the quality of activated carbon, thereby increasing battery performance. In this study, chicken feather waste was chemically activated using $\mathrm{KOH}$ and combined with physical activation at temperature variations of 750,850 and $950{ }^{\circ} \mathrm{C}$. The activation process significantly influenced electrochemical properties because of the difference in their microstructure. The activated carbon pyrolyzed at $850{ }^{\circ} \mathrm{C}(\mathrm{CFCA}-850)$ shows the highest discharge capacity of $285.78 \mathrm{mAhg}^{-1}$, good cycling stability and rate performance due to its higher interlayer spacing and large surface area. Furthermore, electronic conductivity and ion increase, thus improve battery performance.
\end{abstract}

Keywords Activated carbon $\cdot$ Chicken feather $\cdot$ Chemical activation $\cdot$ Batteries

\section{Introduction}

The use of electronic devices in the community causes the need for batteries as electrical energy storage increases. Lithium-ion batteries (LIBs) have received increasing interest in recent years due to their high-energy densities, long cycle lives, and environmental friendliness. At present, carbon materials are generally used as electrode materials for LIBs due to their small surface change, structural stability during cycling, high-energy density, lightweight, and long lifespan, and abundance [1, 2]. However, most of the electrodes exhibit slow diffusivity of lithium ions due to their low active surface area, limiting the inner capacitive contribution of the active material, resulting in insufficient power and energy density [3].

Unfortunately, the source and electrical energy storage are now mainly based on fossil fuels that are finite and not

Erna Hastuti

erna@fis.uin-malang.ac.id

1 Department of Physics, Universitas Islam Negeri Maulana Malik Ibrahim Malang, J1. Gajayana 50, Malang 65144, Indonesia

2 Research Center for Physics, Indonesian Institute of Sciences (LIPI), Komplek PUSPIPTEK Tangerang Selatan, Banten 15314, Indonesia renewable. Therefore, to build a sustainable future, energy storage materials are non-fossil based produced using renewable resources via simple, low cost, and environmentally friendly methods, with controllable morphologies, high porosity, modified surface chemistry, and appropriate functionalities [4].

Carbon is a material that can store energy because of its good performance, environmentally friendly, and inexpensive [5]. Commonly, carbons are taken from fossil sources, which non-renewable, so alternative solutions are essential. Biomass derived from plant and animal waste is a promising alternative because cheap, renewable, environmentally friendly, and abundant. Biomass is a natural resource for producing carbon material [6]. It contains organic chemical elements, such as hydrogen, nitrogen, oxygen, boron, sulfur, and other elements that influence yield, microstructure, conductivity, and capacitance [7]. The composition of these elements causes the type of biomass effect on the carbon produced. The activated carbon is derived from plant-based biomass such as rice husk [8], banana peel [9], cotton [10] using various activation methods.

In addition to plant-based that contain cellulose, animal-based precursors such as hairs, horns, claws, and hooves of animals are attractive kinds of biomass consisting of a fibrous structural protein called keratin. Keratin is a fibrous protein that contains sulfur, glycine, cysteine, 
proline, and serine [11]. Unlike cellulose, keratin gains chemical and thermal stability due to its intermolecular bonding, including non-covalent hydrogen bonds, ionic salt bonds, and covalent disulfide cystine crosslinking [12]. Keratin can be obtained from human hair [13], wool [14], and chicken feathers [15]. Chicken feather waste in the agricultural industry is increasing due to the higher demand for chickens and has become a promising candidate for porous carbon with a high capacity [16]. Therefore, solutions are needed to utilize waste to add economic value and become a solution to environmental problems. On the other hand, chicken feathers can produce keratin with functional groups $\mathrm{N}-\mathrm{H}, \mathrm{C}-\mathrm{H},-\mathrm{CH}_{2}-\mathrm{S}, \mathrm{C} \equiv \mathrm{N}, \mathrm{C}-\mathrm{O}$, and $\mathrm{CH}_{2}$ [17].

Recently, many attempts were made to make carbon with a large surface area, high pore volume, and high conductivity suitable for battery electrodes, such as the activation process. Chemical activation methods using $\mathrm{KOH}$ on chicken feather carbon have been carried out [16]. The specific area, pore structure, and specific capacitance are affected significantly by the activation process. However, the chemical activation also reduces the carbon electrode's conductivity and density, leading to poor rate performance and low volumetric energy density [18].

Therefore, this study conducted a combination of chemical and physical activation. Chicken feathers that have been carbonized at low temperatures are then chemically activated using $5 \mathrm{M} \mathrm{KOH}$. We investigated the physical activation with the pyrolysis process at varying temperatures of 750 , 850 , and $950{ }^{\circ} \mathrm{C}$. The activated carbon was then characterized by X-ray diffraction, Raman spectrometer, gas adsorption analyzer, and its effect on the LIB performance.

\section{Experimental}

\section{Sample preparation}

Carbonized chicken feather (CFC) from chicken feather was prepared by the pyrolysis method, which describes in detail in our previous work [19]. Activated carbons were obtained through chemical activation, followed by physical activation with heat treatment under nitrogen $\left(\mathrm{N}_{2}\right)$ flow. First, $\mathrm{CFC}$ was impregnated in $5 \mathrm{M} \mathrm{KOH}$ solution at room temperature for $24 \mathrm{~h}$. Then, the sample was washed with $1 \mathrm{M} \mathrm{HCl}$ and distilled water. Second, different temperature variations were carried out to determine the physical activation of carbon. The samples were heated at 750,850 , and $950{ }^{\circ} \mathrm{C}$ for three $\mathrm{h}$ under $\mathrm{N}_{2}$ atmosphere (flow rate $50 \mathrm{ml} \mathrm{min}^{-1}$ ) at the heating ratio of $5{ }^{\circ} \mathrm{C} \mathrm{min}^{-1}$. The obtained activated carbons are denoted as CFCA-750, CFCA-850, and CFCA-950, where 750,850 , and 950 represent the heating temperature.

\section{Characterization}

The crystallographic structure of materials was determined by an X-ray diffractometer (XRD, Philips X-Pert) using $\mathrm{Cu}-\mathrm{K} \alpha$ radiation. To verify the degree of graphitization, Raman Spectroscopy was performed employing a (Horiba Scientific) using the $785 \mathrm{~nm}$ line laser. The morphological observations of CFC and CFCAs were performed by scanning electron microscope (SEM, Hitachi SU3500). The pore structure of CFCAs was analyzed by nitrogen adsorption/desorption isotherm at 77.3 K (Quanta chrome, NOVA High-Speed Gas Sorption Analyzer Version 11.30). The surface area (SBET) was determined by applying the BET method in the partial pressure range of $0.05-0.30$. The pore volume and the pore diameter were obtained using the BJH (Barrett-Joyner-Halenda) equation.

\section{Electrochemical}

The electrodes were prepared by mixing $80 \mathrm{wt} . \%$ CFCAs, 10 wt.\% super P carbon black, and 10 wt.\% PVDF with dispersed and dissolution in $\mathrm{N}-\mathrm{N}$ Dimethyl Acetamide (DMAC). The slurry was coated on $\mathrm{Cu}$ foil and dried at $70{ }^{\circ} \mathrm{C}$ for an hour. The coin cells were assembled in a glove box using half cell types. All samples are becoming working electrode and Li metal as a counter side. Polystyrene (PE) was used as a separator and electrolyte salt, 1 M LiPF6 in organic solvent, ethylene carbonate/ethyl methyl carbonate (EC/EMC) with composition 3:7 in volume, with $2 \%$ additive vinyl carbonate (VC). Galvanostatic charge and discharge tests of the cells were performed on (WBCS3000) in the potential range of $0-2 \mathrm{~V}$ at a different rate of $0.25 \mathrm{C}, 0.5 \mathrm{C}, 1 \mathrm{C}, 2 \mathrm{C}$, and $4 \mathrm{C}$. The cyclic voltammetry (CV) measurements were conducted on the same instrument in the potential range of $0.06-3 \mathrm{~V}$ with scanning rate of $0.1 \mathrm{mV} \mathrm{s}^{-1}$. Electrochemical impedance spectroscopy (EIS) was tested in the frequency range from $2 \mathrm{kHz}$ to $0.1 \mathrm{~Hz}$ with a potential amplitude of $0.2 \mathrm{~V}$.

\section{Result and discussion}

The diffractogram of carbon powder with variations of activation temperature is presented in Fig. 1. The diffraction pattern shows the presence of carbon (C) phase in all carbonized samples. Two broad diffraction peaks around $2 \theta=25^{\circ}$ and $45^{\circ}$ corresponding to the plane (002) and (011) exhibit poor crystallinity. The plane (011) indicating $\mathrm{sp}^{2}$ structure of carbon [6]. Compared with CFC sample, the characteristic peak of activated carbon is higher in intensity. The results verify that activated temperature enhances the regularity 


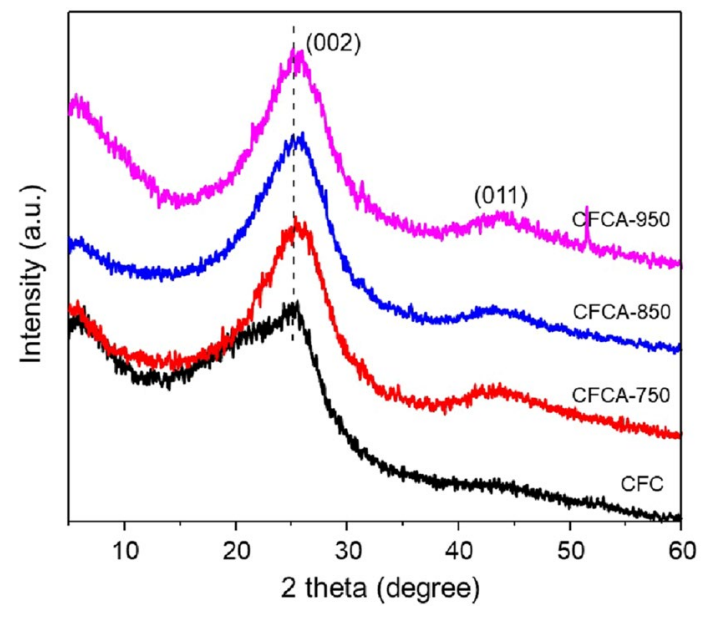

Fig. 1 XRD pattern of keratin and CFCAs

Table 1 Structural properties of CFC and CFCAs

\begin{tabular}{llll}
\hline Sample & $d_{(002)}(\mathrm{nm})$ & $L_{a}(\mathrm{~nm})$ & $L_{c}(\mathrm{~nm})$ \\
\hline CFC & 0.358 & - & 0.94 \\
CFCA-750 & 0.348 & 2.915 & 1.18 \\
CFCA-850 & 0.351 & 4.58 & 1.28 \\
CFCA-950 & 0.347 & 4.011 & 1.18 \\
\hline
\end{tabular}

Fig. 2 Raman spectra of keratin and CFCAs of crystalline structure. Furthermore, the peak shift to the right side after activation, from which it can be indicated evaporation of volatile substances and interaction nitrogen with carbon.

The peak shift is inversely proportional to the value of interlayer spacing $(d)$ according to the Bragg's equation. The value of $d_{(002)}$ declines after the activation process with values of $0.358,0.348,0.351$ and $0.347 \mathrm{~nm}$ for CFC, CFCA750, CFCA-850 and CFCA-950, respectively. Decrease in the interlayer distances indicating that carbon planes become closer to each other, caused by evaporation of volatile substances in the carbon. The interlayer spacing, height $\left(L_{c}\right)$ and width $\left(L_{a}\right)$ of the carbon are calculated based on the Scherrer equation, using the full width at half maximum (FWHM) value of the (002) peak [20]. Table 1 shows that the size of $L_{c}$ and $L_{a}$ enlarged after activation process, indicated the growth and arrangement of crystal.

The further chemical structure of CFC and CFCAs were studied using Raman spectroscopy, as shown in Fig. 2. The Raman spectra were de-convoluted using a mixed Lorentzian-Gaussian function. The spectra exhibited the same appearance in all samples: two well-resolved bands, namely $D\left(\sim 1320 \mathrm{~cm}^{-1}\right)$ and $G\left(\sim 1580 \mathrm{~cm}^{-1}\right)$ band. The presence of $G$ band indicates the graphite, which contains $\mathrm{sp}^{2}$ carbon network ( $\mathrm{E}_{2 \mathrm{~g}}$ symmetry). The intensity of $D$ band $\left(\mathrm{A}_{1 \mathrm{~g}}\right.$ symmetry) can be used to observe the density of defects and the disorder (porosity, crystallite size distribution, and the concentration of amorphous component) in the structure
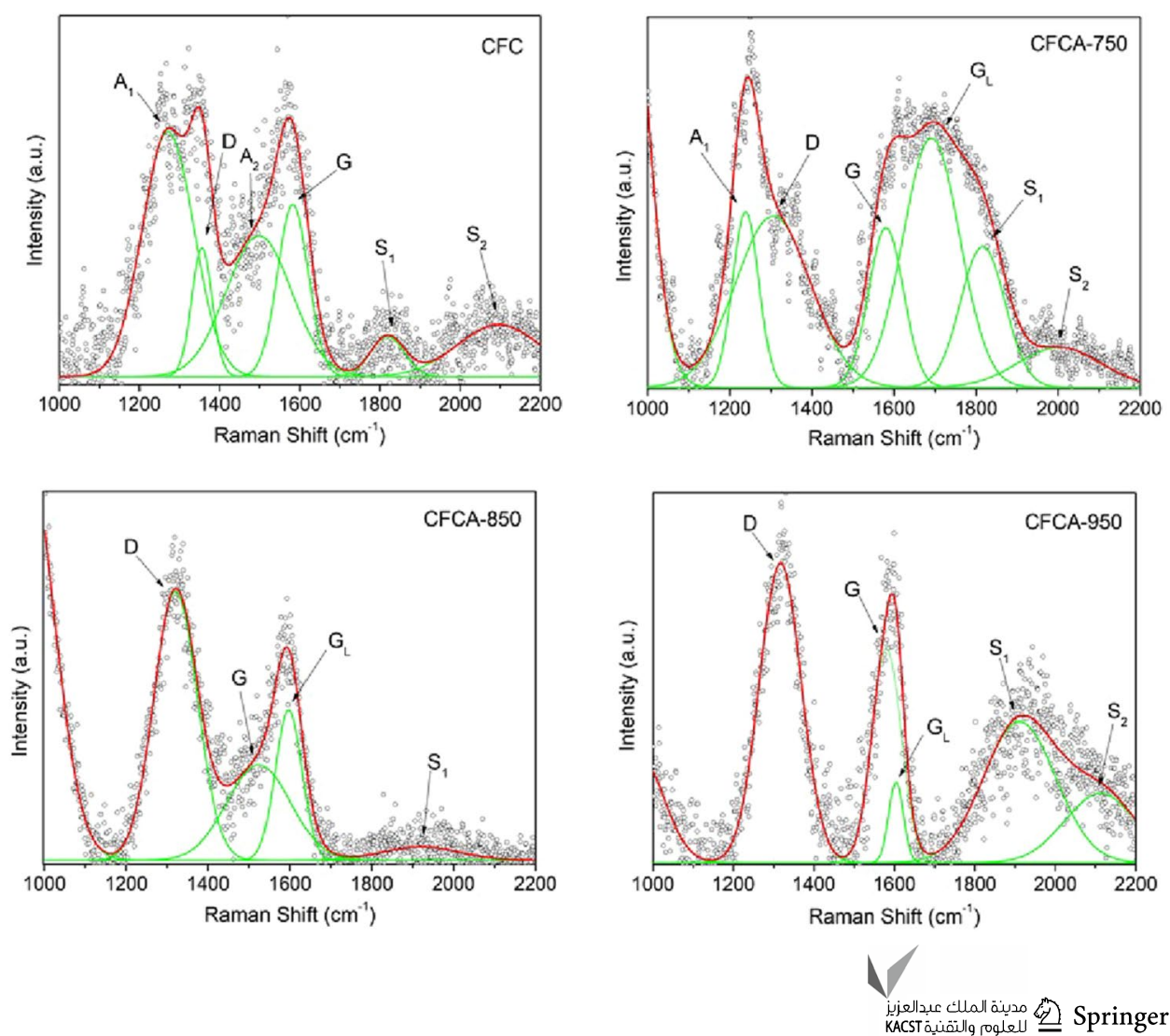
[21]. The $I_{D} / I_{G}$ ratio also depends on the rates of the $\mathrm{sp}^{3}$ and $\mathrm{sp}^{2}$ areas and the $\mathrm{O} / \mathrm{C}$ ratio [22]. The intensity ratio $I_{D} /$ $I_{G}$ arises with the chemical and temperature activation given in Table 2. In the CFC sample, $I_{D} / I_{G}<1$, that shows small irregularity. $I_{D} / I_{G}$ ratio becomes larger than 1 with an increase in temperature. The highest intensity ratio $I_{D} / I_{G}$ at the CFCA-850 sample (1.789) shows many irregularities and indicates the addition of structural defects [23]. This result suggests that the structure's oxygen content increases with temperature, and the $\mathrm{sp}^{2}$ carbon components decrease. Besides, the expansion of these peaks with temperature indicates the increase of structural defects. Peak $D$ is caused by $\mathrm{sp}^{3}$ hybridization vibration, and vibrations of $\mathrm{sp}^{2}$ carbon networks cause $G$ peak.

Additional broad absorption is observed in Raman spectra of CFC, around $1490 \mathrm{~cm}^{-1}\left(A_{2}\right.$ band), attributed to amorphous carbon on the interstitial position of graphite [24] and $\sim 1270 \mathrm{~cm}^{-1}$ ( $A_{l}$ band) represent $\mathrm{sp}^{2}-\mathrm{sp}^{3}$ or the $\mathrm{sp}^{3}$-rich carbonaceous structures [25]. Activation processes decrease the amorphous peaks ( $A_{1}$ and $A_{2}$ bands), and graphitic peaks appear around $1600 \mathrm{~cm}^{-1}\left(G_{L}\right.$ band) at CFCA750 and CFCA-950. $G_{R}$ band at CFCA-850 corresponds to the aromatic structure in amorphous carbon. Furthermore, $S_{1}$ and $S_{2}$ bands in the $1800-2000 \mathrm{~cm}^{-1}$ range indicate which is related to vibrations of linear carbon chains [26].

Calculation of crystallite size $\left(L_{a}\right)$ using Raman data showed a significantly different value compared to XRD results. These differences likely because of Raman spectroscopy's capacity to detect smaller shifts in interatomic vibrational frequency caused by the stress-induced changes in strain due to the presence of defects. However, these results demonstrate that both techniques are complementary to each other and are highly sensitive to small changes in the crystal structure [27].

The typical nitrogen adsorption isotherms of all CFCAs are shown in Fig. 3. Increases in volume at low relative pressure indicate that the CFCA-850 and CFCA-950 samples presence of micropores and narrow pore size distribution consistent with type I(a) (according to IUPAC classification, [28]). While CFCA-750 samples possess mesopores structure and CFC sample possess macropores. Absorbed volume gradually rises with the increase of temperature

Table 2 Raman analysis- $I_{D} / I_{G}$ ratio and surface crystalline size of $\mathrm{CFC}$ and CFCAs

\begin{tabular}{lllll}
\hline Sample & \multicolumn{2}{l}{ Raman shift $\left(\mathrm{cm}^{-1}\right)$} & $I_{D} / I_{G}$ & \multicolumn{2}{l}{$L_{a}(\mathrm{~nm})=4.4 / R$} \\
\cline { 2 - 3 } & \multicolumn{1}{l}{$G$ Band } & $D$ Band & & \\
\hline CFC & 1582 & 1355 & 0.748 & 5.882 \\
CFCA-750 & 1581 & 1306 & 1.072 & 4.104 \\
CFCA-850 & 1596 & 1320 & 1.789 & 2.459 \\
CFCA-950 & 1580 & 1317 & 1.394 & 3.156 \\
\hline
\end{tabular}

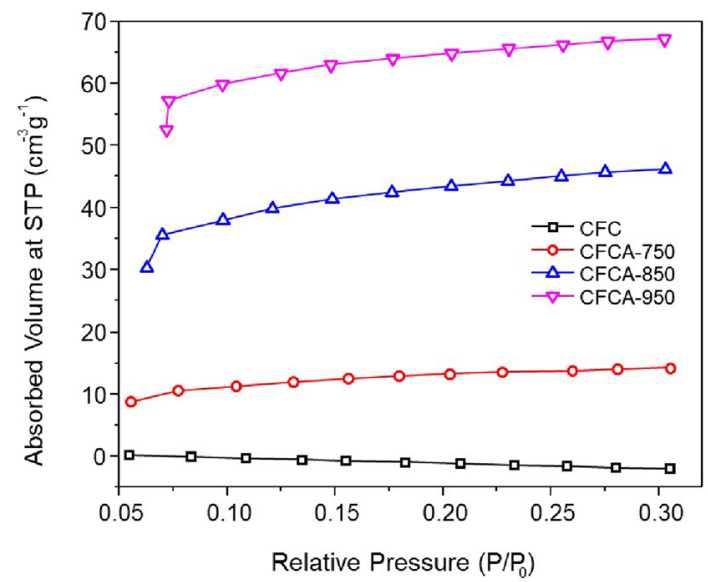

Fig. $3 \mathrm{~N}_{2}$ adsorption of keratin and CFCAs

activation. This activation changes pore size, because most mesopores break at a higher temperature, and the pore diameter decreases [29].

Pore structure parameters of CFC and CFCAs are summarized in Table 3. The specific surface area of CFCA-750, CFCA-850, and CFCA-950 samples are $44.76 \mathrm{~m}^{2} \mathrm{~g}^{-1}, 144.66$ $\mathrm{m}^{2} \mathrm{~g}^{-1}$, and $204.91 \mathrm{~m}^{2} \mathrm{~g}^{-1}$, respectively, and it indicates that the CFCA-950 sample has an advantage of higher specific capacitance than others due to the highest surface area.

The morphologies of CFC and CFCAs were investigated by scanning electron microscopy. As shown in Fig. 4a, CFC morphology displays grain with varied sizes and large porosity with a diameter of around $27.47 \mu \mathrm{m}$. However, the grain of CFCAs (Fig. 4b-d) becomes smaller and uniform with average diameter around $23 \mu \mathrm{m}$. By further increasing the enlargement, it is possible to observe the surface of carbon and activated carbon. The chemical and physical activation processes on the carbon display similar morphologies and no significant changes or structural distortions were observed. CFC sample shows a smooth surface and a series of streaks through the surface (Fig. 4a inset), while the surface of activated carbon appears smooth surface with small fragments and an increasing number of stripes (Fig. 4b-d inset). During the high-temperature process, the $\mathrm{CFC}$ was activated into conductive CFCA accompanied by the release of gaseous

Table 3 BET surface area and pore parameters of CFC and CFCAs

\begin{tabular}{llll}
\hline Sample & $\begin{array}{l}\text { BET surface area } \\
\left(\mathrm{m}^{2} \mathrm{~g}^{-1}\right)\end{array}$ & $\begin{array}{l}\text { Pore volume } \\
\left(\mathrm{cm}^{3} \mathrm{~g}^{-1}\right)\end{array}$ & $\begin{array}{l}\text { Pore } \\
\text { diameter } \\
(\mathrm{nm})\end{array}$ \\
\hline CFC & - & 0.011 & 290.74 \\
CFCA-750 & 44.76 & 0.005 & 97.16 \\
CFCA-850 & 144.66 & 0.010 & 3.42 \\
CFCA-950 & 204.91 & 0.008 & 3.08 \\
\hline
\end{tabular}


Fig. 4 SEM images of: a CFC; b CFCA-750; c CFCA-850; d CFCA-950
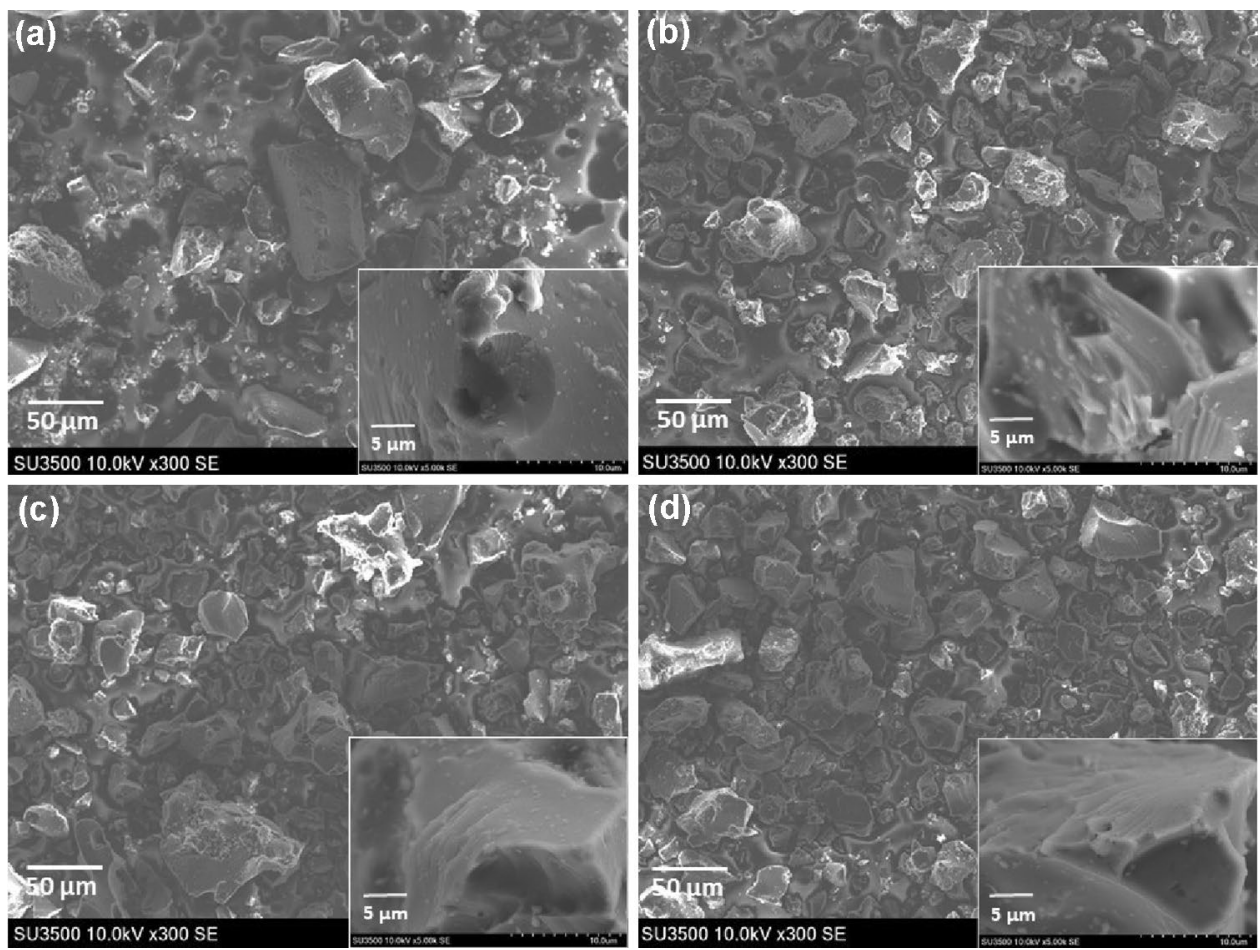

by-products such as $\mathrm{CH}_{4}, \mathrm{H}_{2}, \mathrm{CO}$, and $\mathrm{CO}_{2}$ [30]. The activation process yields a surface reaction, which facilitate the formation of the porous structure of the CFCAs.

EIS is a powerful tool to investigate the dynamic information of ion transport and charge transfer. As shown in Fig. 5, all curves displayed a semicircle at high frequency and a line in low frequency. The intercept on the $Z^{\prime}$ axis in the highfrequency region relates to the ionic conductivity of the electrolyte passing through SEI on the electrode surface $\left(R_{\mathrm{SEI}}\right)$. The semicircles in the high-to-medium-frequency range are associated with the charge transfer between the electrolyte and the electrode material $\left(R_{\mathrm{ct}}\right)$ [31]. At low frequencies $(0.1-20 \mathrm{~Hz})$, the typical Warburg behavior can be attributed to the solid-state diffusion of lithium ions (Fig. 5b).

As seen from Table $4, R_{\mathrm{SEI}}$ and $R_{\mathrm{ct}}$ values decrease with the number of temperature activation. The $R_{\mathrm{ct}}$ values of activated carbon increased follow the order of CFCA$950<$ CFCA-850 < CFCA-750 < CFC. It is speculated that the low $R_{\mathrm{ct}}$ of the CFCAs is due to its high specific surface area, which facilitates intercalation and de-intercalation
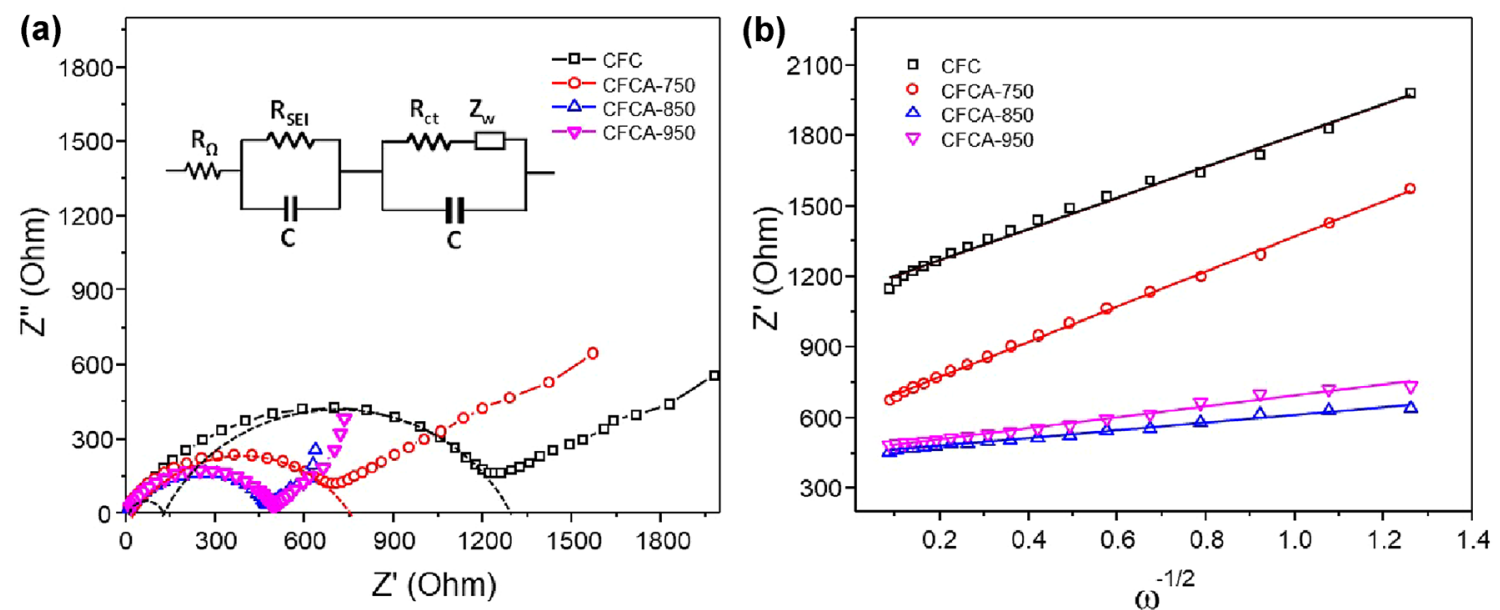

Fig. 5 a Electrochemical impedance spectra, and $\mathbf{b}$ the linear relationship between the Warburg impedance and the inverse square root of angular frequency of CFC and CFCAs 
Table 4 EIS parameters and $\mathrm{Li}$-ion diffusion of $\mathrm{CFC}$ and CFCAs

\begin{tabular}{llllll}
\hline Sample & $R_{\text {SEI }}(\mathrm{ohm})$ & $R_{\mathrm{ct}}(\mathrm{ohm})$ & Conductivity $\left(\mathrm{Scm}^{-1}\right)$ & $\sigma_{\omega}\left(\Omega_{\mathrm{m}}^{2} \mathrm{~s}^{-1 / 2}\right)$ & $D_{\mathrm{Li+}}\left(\mathrm{cm}^{2} \mathrm{~s}^{-1}\right)$ \\
\hline CFC & 70 & 1190 & $5.27 \times 10^{-6}$ & 638.62 & $1.14 \times 10^{-15}$ \\
CFCA-750 & 41.5 & 656 & $9.56 \times 10^{-6}$ & 735.96 & $8.59 \times 10^{-16}$ \\
CFCA-850 & 37 & 440.5 & $1.42 \times 10^{-5}$ & 162.14 & $1.77 \times 10^{-14}$ \\
CFCA-950 & 36 & 440 & $1.43 \times 10^{-5}$ & 237.52 & $8.25 \times 10^{-15}$ \\
\hline
\end{tabular}

process into/from activated carbon. The vertical line in the CFCA-850 and CFCA-950 were larger than $45^{\circ}$, indicating much lower diffusive resistance compared with CFCA-750 and CFC, which have angles smaller than $45^{\circ}$.

The diffusion value of lithium ions depends on the Warburg constant, known from the regression graph of the relationship between $Z^{\prime}$ (real impedance) and $\omega^{-1 / 2}$, as shown in Fig. 5b. The values of conductivity, Warburg impedance $\left(\sigma_{\omega}\right)$, and lithium-ion diffusion $\left(D_{\mathrm{Li}+}\right)$ are shown in Table 4.

The activation process enhanced the electrical conductivity of electrode by reducing particle size and creating defects that improving the kinetic performance. The CFCA-950 has a higher conductivity than CFCA-750 and CFCA-850 with values of $1.43 \times 10^{-5}, 9.56 \times 10^{-6}, 1.42 \times 10^{-5} \mathrm{Scm}^{-1}$, respectively. The small and uniform particle size of the CFCA-950 sample facilitates movement and shortens the mileage of the ion. Distortion in the sample increases the number of holes, therefore, rises the charge transferred. Ion diffusion will also be easier to occur in crystallites with large $d$ values, because lithium ions $(0.069 \mathrm{~nm})$ have a reasonably wide diffusion path. This causes the diffusion of ions in samples without activation has a higher value than the activation sample temperature of $750{ }^{\circ} \mathrm{C}$. Furthermore, defect in carbon increases the number of holes, allowing more charges quickly to move.

Figure 6 compares the CV curves of CFC and CFCAs with various temperature activation in a potential window of $0.1-2 \mathrm{~V}$ at the same scan rate of $120 \mu \mathrm{V} / \mathrm{s}$. There are reduction peaks in the potential range of $0.8-1.2 \mathrm{~V}$ in the first cycle, corresponding to the irreversible reactions between the activated carbon electrode and electrolyte. This reduction peak disappeared from the second cycle. The difference between the first cycle and second cycle is due to the incomplete conversion reaction and irreversible lithium loss as a result of the formation of the SEI (Solid Electrolyte Interface) layer. The graph shows that the higher of activation temperature, the sharper of oxidation peak formed. This peak indicates an increase in the acceleration rate of intercalation and de-intercalation processes. The highest peak is CFCA-950, with a working voltage $0.40 \mathrm{~V}$ and $I_{\mathrm{pc}}$ value of $0.28 \mathrm{~mA}$. The high surface area of CFCAs with micropores
Fig. $6 \mathrm{CV}$ curves of $\mathrm{CFC}$ and CFCAs
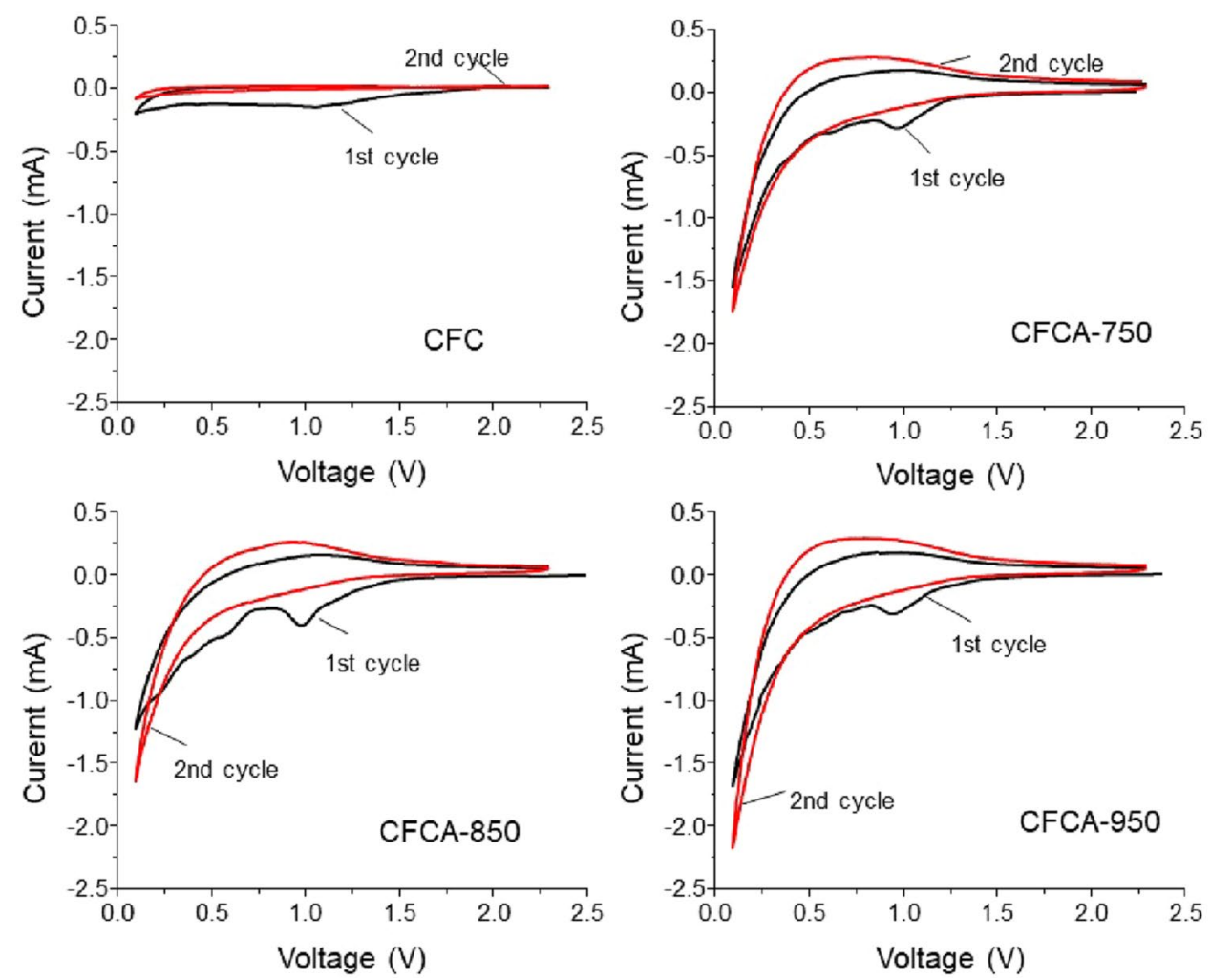
and mesopores provides more active sites for Li-ion adsorption and insertion/extraction on surfaces or defect electrodes.

Charge-discharge curves evaluated the electrochemical performance of CFC, and CFCAs electrodes with different temperature activation are given in Fig. 7. CD test was carried out at the rate of the current density of the $0.25 \mathrm{C}$. The activation temperature raises the charging capacity. The CFCA-950 sample has the highest charging capacity of $260.34 \mathrm{mAhg}^{-1}$, while the CFC sample has the lowest at $1.95 \mathrm{mAhg}^{-1}$. This is because the activated sample can absorb the most lithium ions. The discharge curves show three different potential regions, which may be attributed to different mechanisms. The area from 0 to $0.12 \mathrm{~V}$ corresponds to the de-intercalation of lithium ions from the micropores in the randomly oriented stacks of small constituent molecules. The region from 0.12 to $0.8 \mathrm{~V}$ is ascribed to the de-intercalation of lithium ions from the disordered graphene layers. The area above $0.8 \mathrm{~V}$ corresponds to the de-intercalation of lithium from a variety of edge sites or

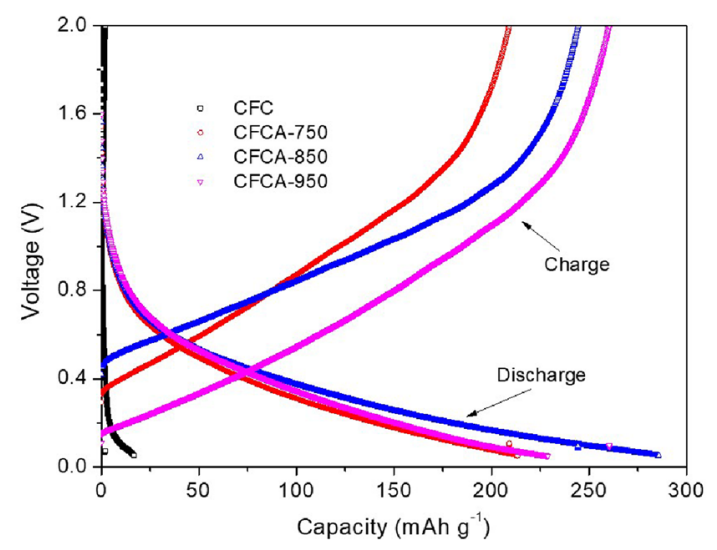

Fig. 7 Discharge/charge profile of CFC and CFCAs the $\mathrm{H}-/ \mathrm{O}-$ containing functional groups in the graphene layer [32].

In this research, all of the discharge curves of electrodes have two voltage plateau regions, reducing $\mathrm{Li}$-ion during the discharge process. The intercalation of $\mathrm{Li}+$ ions in the cell with the CFCAs electrode begins at around $0.5-0.8 \mathrm{~V}$ during charging. This is due to the irreversible formation of a solid electrolyte interface layer on the carbon surface resulting from electrolyte decomposition subsequent reduction with $\mathrm{Li}^{+}$ions [1].

The initial discharge capacity of CFCA- 850 cells was $285.78 \mathrm{mAhg}^{-1}$, comparable to CFCA-950 and CFCA-750 cells (228.92 and $213.40 \mathrm{mAhg}^{-1}$ ) and much higher than CFC cell $\left(16.86 \mathrm{mAhg}^{-1}\right)$. The charge and discharge capacity of a battery are affected by the surface area and pore distribution. The distribution of pore mesoporous $(2-5 \mathrm{~nm})$ will increase the absorption of lithium ions to increase the capacity. The size of a large surface area and pore distribution of mesoporous optimize the battery capacity.

As indicated in Fig. 8a, b, the cycle durability was also obtained. The capacity remains without any decay after 50 cycles, and coulombic efficiency can retain nearly $100 \%$. Discharge capacity of $1^{\text {st }}$ and $50^{\text {th }}$ cycles and retention capacity are shown in Table 5. The CFC cell has the highest retention value (82.64\%), whereas the CFCAs electrode has a larger discharge capacity $\left(102.53,83.40,82.58 \mathrm{mAhg}^{-1}\right.$ for CFCA-750, CFCA-950, and CFCA-850, respectively) than $\mathrm{CFC}$ cell $\left(2.09 \mathrm{mAhg}^{-1}\right)$. Amorphous carbon materials show poor capacity retention during their cycle life due to variations in surface morphology, large voids, disordered non-crystallized sites, random lattice structures, and low specific areas. The activation process causes the rearrangement of the atomic structure in the sample to be unstable and easily decomposed. The damage causes the number of lithium ions intercalating or de-intercalating to decrease so
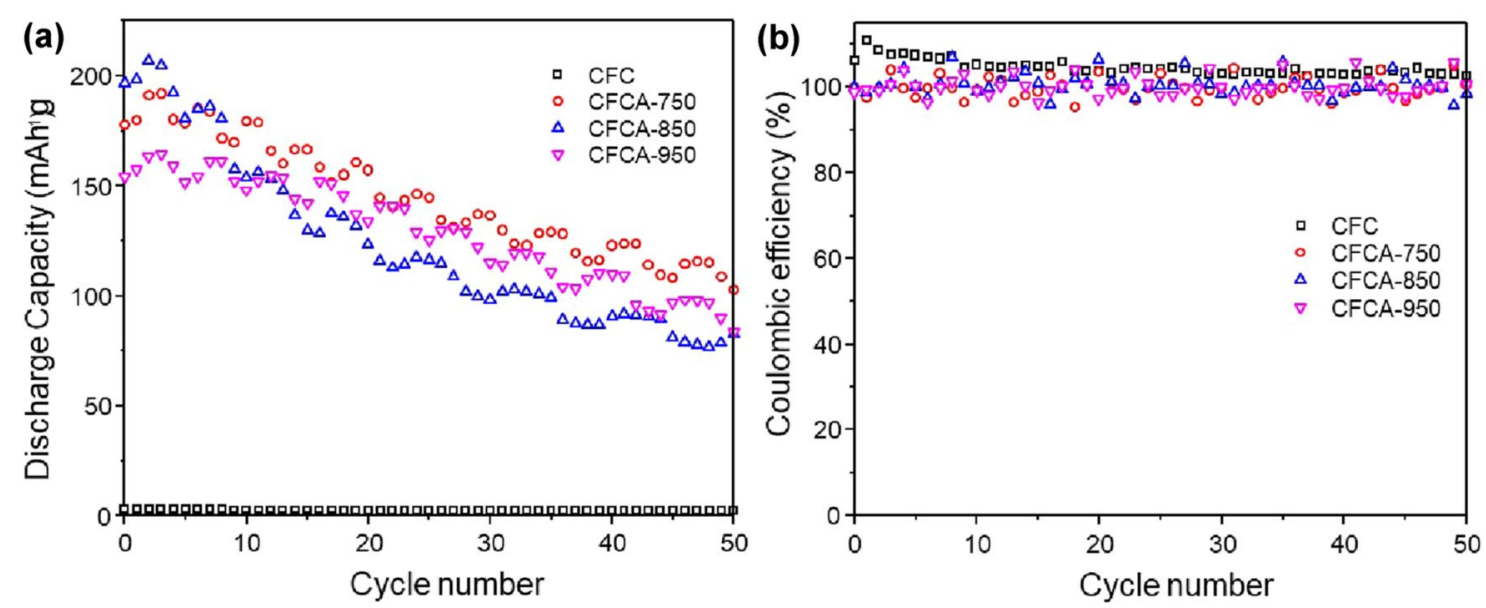

Fig. 8 a Cycling performance, and $\mathbf{b}$ columbic efficiency of CFC and CFCAs 
Table 5 Capacity retention of CFC and CFCAs at C/3

\begin{tabular}{lccc}
\hline Sample & $\begin{array}{l}\text { Discharge capacity } \\
(1 \text { st cycle })\left(\mathrm{mAhg}^{-1}\right)\end{array}$ & $\begin{array}{l}\text { Discharge capac- } \\
\text { ity }(50 \text { th cycle }) \\
\left(\mathrm{mAhg}^{-1}\right)\end{array}$ & $\begin{array}{l}\text { Capacity } \\
\text { retention } \\
(\%)\end{array}$ \\
\hline CFC & 2.45 & 2.09 & 82.64 \\
CFCA-750 & 177.76 & 102.53 & 57.68 \\
CFCA-850 & 196.67 & 82.58 & 41.99 \\
CFCA-950 & 154.39 & 83.40 & 54.02 \\
\hline
\end{tabular}

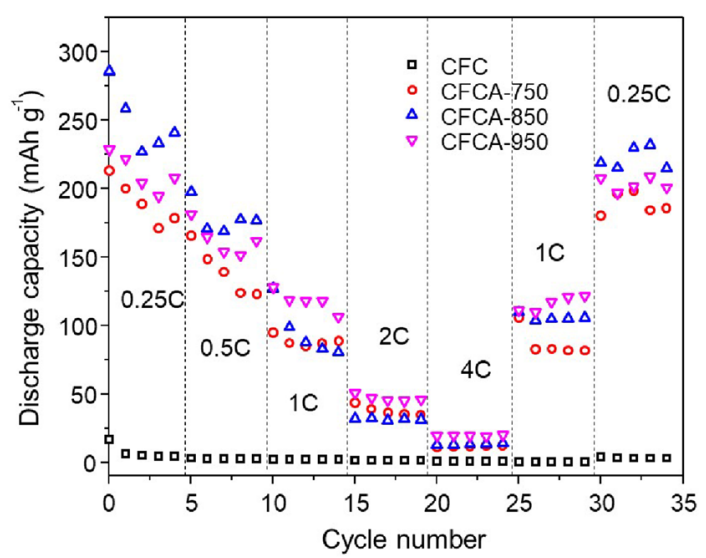

Fig. 9 Rate capability of CFC and CFCAs

that the capacity decreases. Life cycle decline can also occur due to the SEI. Reversible formation/dissolution of SEI-like product on the surface assisted in ion exchange and created more electroactive sites for electrochemical reactions [33]. With increasing charge-discharge rates, the immobilized lithium was found to increase in a similar manner for all cycling rates. This indicates a continuous growth of the SEI with minor dependence on the cycling rate [34]. While the capacity-fade increased with rising cycling rate, the SEI growth was found similar for both cycling paths, which indicates a significant influence from separate aging effect. At all CFCAs sample, a major portion of the SEI was formed after 4 cycles.

The C-rate performance of these electrodes was also investigated with various $\mathrm{C}$-rates from $0.25 \mathrm{C}$ to $4 \mathrm{C}$, as displayed in Fig. 9. The polarization of electrochemical reactions on the electrode could be aggravated with the increasing $\mathrm{C}$-rate, leading to the gradually decreased discharge capacity ranging from 1.09 to $249.12 \mathrm{mAhg}^{-1}$, and resulting in a linear trend with increasing current density.

The chemical and physical activation processes could expand the distance of carbon sheets and produce higher surface area, enhancing the kinetics for intercalation and de-intercalation of lithium ions during charge and discharge processes. Comparing to the case of N-doped carbon-based materials provide improved the electronic conductivity and ion diffusion, resulting in exceptionally stable capacity retention and high capacities [35].

\section{Conclusion}

In this work, activated carbon derived from chicken feather have been successfully prepared by a facile method with incorporation of $\mathrm{KOH}$ activation and physical activation at different temperature. The obtained material exhibits higher interlayer spacing, surface area, and structural defect that contribute to the electrochemical performance of Li-ion batteries. The CFCA-850 electrode exhibited a first-cycle discharge capacity of about $285.78 \mathrm{mAhg}^{-1}$, which is much higher than $16.86 \mathrm{mAhg}^{-1}$ of the CFC electrode. The stability of the CFCAs electrodes was found to be highly stable in terms of charge-storage, with coulombic efficiency about $100 \%$ after 50 cycles. The electrochemical performance of activated carbon in Li-ion batteries is improved compared to un-activated carbon. The electronic conductivity and ion diffusion enhance up to $1.42 \times 10^{-5} \mathrm{Scm}^{-1}$ and $1.77 \times 10^{-14}$ $\mathrm{cm}^{2} \mathrm{~s}^{-1}$ at CFCA-850. This research exhibited that biomassderived chicken feathers are interesting sustainable carbon electrode materials for $\mathrm{Li}$-ion batteries.

Acknowledgements The authors gratefully acknowledge the financial support to this work from Directorate of Islamic Religious Higher Education (PTKI) Ministry of Religious. This research was partially supported by Research Center for Physics, Indonesian Institute for Sciences (LIPI), Tangerang, Indonesia

Author contributions EH (conceptualization, data curation, formal analysis, investigation, methodology, resources, software, visualization, writing, validation). AS (data curation, formal analysis, methodology, investigation, resources, validation). DP (data curation, formal analysis, methodology, resources).

\section{Declarations}

Conflict of interest There are no conflicts to declare.

Open Access This article is licensed under a Creative Commons Attribution 4.0 International License, which permits use, sharing, adaptation, distribution and reproduction in any medium or format, as long as you give appropriate credit to the original author(s) and the source, provide a link to the Creative Commons licence, and indicate if changes were made. The images or other third party material in this article are included in the article's Creative Commons licence, unless indicated otherwise in a credit line to the material. If material is not included in the article's Creative Commons licence and your intended use is not permitted by statutory regulation or exceeds the permitted use, you will need to obtain permission directly from the copyright holder. To view a copy of this licence, visit http://creativecommons.org/licenses/by/4.0/. 


\section{References}

1. Fang, M.-D., Ho, T.-H., Yen, J.-P., Lin, Y.-R., Hong, J.-L., Wu, S.-H., Jow, J.-J.: Preparation of advanced carbon anode materials from mesocarbon microbeads for use in hjigh C-rate lithium ion batteries. Materials 8, 3550 (2015)

2. Gao, Z., Song, N., Li, X.: Microstructural design of hybrid CoO@ $\mathrm{NiO}$ and graphene nano-architectures for flexible high performance supercapacitors. J. Mater. Chem. A 3, 14833 (2015)

3. Gao, Z., Song, N., Zhang, Y., Li, X.: Cotton-textile-enabled, flexible lithium-ion batteries with enhanced capacity and extended lifespan. Nano Lett. 15, 8194 (2015)

4. Gao, Z., Zhang, Y., Song, N., Li, X.: Biomass-derived renewable carbon materials for electrochemical energy storage. Mater. Res. Lett. 5, 69 (2017)

5. Liu, Y., Zeng, Z., Wei, J.: Frontiers in nano-architectured carbon-metal oxide electrodes for supercapacitance energy storage: a review. Front. Nanosci. Nanotechnol. 2, 78 (2016)

6. Arie, A.A., Kristianto, H., Susanti, R.F., Devianto, H., Halim, M., Lee, J.K.: Structural and preliminary electrochemical characteristics of palm oil based carbon nanospheres as anode materials in lithium ion batteries. Carbon Lett. 18, 80 (2016)

7. Liu, Y., Chen, J., Cui, B., Yin, P., Zhang, C.: Design and preparation of biomass-derived carbon materials for supercapacitors: a review. C. 4, 53 (2018)

8. Rybarczyk, M.K., Li, Y., Qiao, M., Hu, Y.-S., Titirici, M.-M., Lieder, M.: Hard carbon derived from rice husk as low cost negative electrodes in Na-ion batteries. J. Energy Chem. 29, 17 (2019)

9. Zhang, Y., Gao, Z., Song, N., Li, X.: High-performance supercapacitors and batteries derived from activated banana-peel with porous structures. Electrochim. Acta 222, 1257 (2016)

10. Gao, Z., Bumgardner, C., Song, N., Zhang, Y., Li, J., Li, X.: Cotton-textile-enabled flexible self-sustaining power packs via roll-to-roll fabrication. Nat. Commun. 7, 11586 (2016)

11. Paul, T., Jana, A., Mandal, A.K., Mandal, A., Das Mohpatra, P.K., Mondal, K.C.: Bacterial keratinolytic protease, imminent starter for NextGen leather and detergent industries. Sustain. Chem. Pharm. 3, 8 (2016)

12. Wang, B., Yang, W., McKittrick, J., Meyers, M.A.: Keratin: Structure, mechanical properties, occurrence in biological organisms, and efforts at bioinspiration. Prog. Mater Sci. 76, 229 (2016)

13. Pramanick, B., Cadenas, L.B., Kim, D.-M., Lee, W., Shim, Y.-B., Martinez-Chapa, S.O., Madou, M.J., Hwang, H.: Human hairderived hollow carbon microfibers for electrochemical sensing. Carbon 107, 872 (2016)

14. Wang, K., Li, R., Ma, J.H., Jian, Y.K., Che, J.N.: Extracting keratin from wool by using L-cysteine. Green Chem. 18, 476 (2016)

15. Alahyaribeik, S., Ullah, A.: Methods of keratin extraction from poultry feathers and their effects on antioxidant activity of extracted keratin. Int. J. Biol. Macromol. 148, 449 (2020)

16. Wang, Q., Cao, Q., Wang, X., Jing, B., Kuang, H., Zhou, L.: J. A high-capacity carbon prepared from renewable chicken feather biopolymer for supercapacitors. Power Sources 225, 101 (2013)

17. Farida, A., Hastuti, E.: Characterization and analysis of crystal structure mixed keratin-magnesium composite with Rietveld method. 6 (2013)

18. Pozio, A., Aurora, A., Prosini, P.P.: Hard carbon for sodium batteries: Wood precursors and activation with first group hydroxide. J. Power Sources 449, 227555 (2020)

19. Hastuti, E., Subhan, A., Auwala, A.: Performance of carbon based on chicken feather with $\mathrm{KOH}$ activation as an anode for Li-ion batteries. Materials Today: Proceedings (2020)

20. Shen, H., Zhang, Y., Song, X., Liu, Y., Wang, H., Duan, H., Kong, $\mathrm{X}$.: Facile hydrothermal synthesis of actiniaria-shaped $\alpha-\mathrm{MnO} 2 /$ activated carbon and its electrochemical performances of supercapacitor. J. Alloy. Compd. 770, 926 (2019)

21. Sisu, C., Iordanescu, R., Stanciu, V., Stefanescu, I., Vlaicu, A.M., Grecu, V.V.: Raman spectroscopy studies of some carbon molecular sieves. 8

22. Wang, J., Zhang, S., Zhou, J., Liu, R., Du, R., Xu, H., Liu, Z., Zhang, J., Liu, Z.: Identifying sp-sp 2 carbon materials by Raman and infrared spectroscopies. Phys. Chem. Chem. Phys. 16, 11303 (2014)

23. Bal Altuntaş, D., Nevruzoğlu, V., Dokumac1, M., Cam, Ş: Synthesis and characterization of activated carbon produced from waste human hair mass using chemical activation. Carbon Lett. 30, 307 (2020)

24. Lazzarini, A., Piovano, A., Pellegrini, R., Leofanti, G., Agostini, G., Rudić, S., Chierotti, M.R., Gobetto, R., Battiato, A., Spoto, G., Zecchina, A., Lamberti, C., Groppo, E.: A comprehensive approach to investigate the structural and surface properties of activated carbons and related Pd-based catalysts. Catal. Sci. Technol. 6, 4910 (2016)

25. Dodevski, V., Stojmenović, M., Vujković, M., Krstić, J., Krstić, S., Bajuk-Bogdanović, D., Kuzmanović, B., Kaluđerović, B., Mentus, S.: Complex insight into the charge storage behavior of active carbons obtained by carbonization of the plane tree seed. Electrochim. Acta 222, 156 (2016)

26. Endo, M., Kim, Y.A., Hayashi, T., Muramatsu, H., Terrones, M., Saito, R., Villalpando-Paez, F., Chou, S.G., Dresselhaus, M.S.: Nanotube coalescence-inducing mode: a novel vibrational mode in carbon systems. Small 2, 1031 (2006)

27. Ram, R., Khastgir, D., Rahaman, M.: Physical properties of polyvinylidene fluoride/multi-walled carbon nanotube nanocomposites with special reference to electromagnetic interference shielding effectiveness. Adv. Polym. Technol. 37, 3287 (2018)

28. Thommes, M., Kaneko, K., Neimark, A.V., Olivier, J.P., Rodriguez-Reinoso, F., Rouquerol, J., Sing, K.S.W.: Physisorption of gases, with special reference to the evaluation of surface area and pore size distribution (IUPAC Technical Report). Pure Appl. Chem. 87, 1051 (2015)

29. Enock, T.K., Kingondu, C.K., Pogrebnoi, A., Jande, Y.A.C.: Status of biomass derived carbon materials for supercapacitor application. Int. J. Electrochem. 2017, 1 (2017)

30. Gao, Z., Schwab, Y., Zhang, Y., Song, N., Li, X.: Ferromagnetic nanoparticle-assisted polysulfide trapping for enhanced lithiumsulfur batteries. Adv. Funct. Mater. 28, 1800563 (2018)

31. Zhang, Y., Gao, Z., Li, X.: Capillarity composited recycled paper/ graphene scaffold for lithium-sulfur batteries with enhanced capacity and extended lifespan. Small 13, 1701927 (2017)

32. Guo, Z., Wang, C., Chen, M., Li, M.: Hard carbon derived from coal tar pitch for use as the anode material in lithium ion batteries. Int. J. Electrochem. Sci. 8, 8 (2013)

33. Wang, A., Kadam, S., Li, H., Shi, S., Qi, Y.: Review on modeling of the anode solid electrolyte interphase (SEI) for lithium-ion batteries. Npj Comput. Mater. 4, 15 (2018)

34. Frankenberger, M., Trunk, M., Seidlmayer, S., Dinter, A., Dittloff, J., Werner, L., Gernhäuser, R., Revay, Z., Märkisch, B., Gilles, R., Pettinger, K.-H.: SEI growth impacts of lamination, formation and cycling in lithium ion batteries. Batteries 6, 21 (2020)

35. Yan, L., Yu, J., Houston, J., Flores, N., Luo, H.: Biomass derived porous nitrogen doped carbon for electrochemical devices. Green Energy Environ. 2, 84 (2017)

Publisher's Note Springer Nature remains neutral with regard to jurisdictional claims in published maps and institutional affiliations. 